\title{
Desempenho de híbridos de girassol em espaçamentos reduzidos
}

\section{Performance of sunflower hybrids in reduced row spacings}

\author{
Alessandro Guerra da Silva ${ }^{1 *}$; Rodrigo Pires²; Eduardo Bezerra de Morães²; \\ Ana Cláudia Barneche de Oliveira ${ }^{3}$; Cláudio Guilherme Portela de Carvalho ${ }^{3}$
}

\section{Resumo}

Com objetivo de avaliar o efeito dos espaçamentos entre linhas nas características agronômicas de três híbridos de girassol, foi conduzido um ensaio no campus experimental da FESURV-Universidade de Rio Verde, em Rio Verde (GO). Foram avaliados os espaçamentos de 40 e $50 \mathrm{~cm}$ combinados com os híbridos Agrobel 960, BRHS 5 e Hélio 251, com 60.000 plantas ha ${ }^{-1}$. O delineamento experimental utilizado foi o de blocos ao acaso, em esquema fatorial $2 \times 3$, com quatro repetições. A semeadura foi realizada no dia 12 de março de 2005 e a colheita em 5 de julho de 2005. Avaliou-se o rendimento de aquênios, o peso de 1.000 aquênios, o diâmetro do capítulo, o número de aquênios por capítulo e a altura de plantas. Os resultados foram submetidos a análise de variância e as médias comparadas pelo teste de Tukey a 5\%. O maior rendimento de aquênios foi obtido com o híbrido de girassol Agrobel 960, sendo também o de menor estatura. Não houve diferenças significativas entre os híbridos para o peso de 1.000 aquênios, diâmetro do capítulo e número de aquênios por capítulo. $\mathrm{O}$ espaçamento de $40 \mathrm{~cm}$ permitiu a obtenção de maior rendimento e número de aquênios por capítulo, porém com menor peso de 1.000 aquênios. O efeito de espaçamento entre linhas não influenciou o diâmetro dos capítulos e a altura de plantas.

Palavras-chave: Helianthus annuus, rendimento, componentes do rendimento

\begin{abstract}
With the objective of evaluating the effect of row spacing in the agronomic characteristics of three hybrids of sunflower, a trial was carried out on the FESURV-Universidade de Rio Verde experimental campus in Rio Verde, GO. The hybrids Agrobel 960, BRHS 5 and Hélio 251 were evaluated, with 60.000 plants $\mathrm{ha}^{-1}$ in the row spacings of 40 and $50 \mathrm{~cm}$. The random blocks design was used, in a $2 \times 3$ factorial scheme, with four replications. The planting was at March, 2005, and the harvest was at July. It was evaluated the achene yield, one thousand achenes weight, capitulum size, number of achenes per capitulum and plant height. The results were subjected to analysis of variance and the means compared by Tukey test. Agrobel 960 hybrid presented the highest achene yield and the smallest height. The sunflower hybrids had no significant differences for one thousand achene weight, capitulum size and number of achenes per capitulum. The $40 \mathrm{~cm}$ row spacing presented the highest achene yield and number of achenes per capitulum, but the smallest one thousand achene weight. The effect of row spacings had no influence on capitulum size and plant height.
\end{abstract}

Key words: Helianthus annuus, yield, yield components

\footnotetext{
1 Professor da Faculdade de Agronomia da FESURV-Universidade de Rio Verde, Caixa Postal 104, Rio Verde, GO. E-mail: silvaag@yahoo.com.br.

2 Acadêmicos do curso de Agronomia/FESURV. Universidade de Rio Verde. Rio Verde, GO.

3 Pesquisadores da Embrapa Soja, Londrina, PR.

* Autor para correspondência
} 


\section{Introdução}

Nos últimos anos, muitos agricultores da região Centro-Oeste têm cultivado o girassol após a colheita da safra principal de verão, no período conhecido como safrinha. A opção pelo cultivo dessa oleaginosa está no fato de ser uma excelente espécie para a rotação e sucessão de culturas apresentando benefícios para a cultura sucessora (SILVA; RIZZARD, 1993; ROSSI, 1998; AMABILE; FERNANDES; SANZONOWICZ, 2002; PEREIRA; VELINI, 2003; TOMICH et al., 2003; SODRÉ FILHO et al., 2004). Além disto, o girassol permite a obtenção de grãos para produção de óleo na entressafra, diminuindo a capacidade ociosa das indústrias.

A avaliação da distribuição de plantas de girassol na área de cultivo é importante quando o objetivo principal é a obtenção de maiores rendimentos de aquênios. Antes do advento das indústrias de máquinas agrícolas, a escolha do espaçamento entre linhas para o cultivo de girassol se baseava nas características dos implementos e colhedoras existentes no mercado nacional, sendo empregados espaçamentos maiores ou iguais a $70 \mathrm{~cm}$ para o cultivo dessa oleaginosa. Atualmente, existem maquinários disponíveis no mercado que permitem o cultivo do girassol em espaçamentos menores que $70 \mathrm{~cm}$.

$\mathrm{O}$ aumento no rendimento de aquênios obtido com a distribuição adequada de plantas de girassol na área de cultivo é atribuído ao acréscimo da população de plantas colhidas, ao maior número de aquênios por capítulo e ao maior peso dos aquênios (SILVA et al., 1995). Para a escolha do arranjo de plantas ideal para a cultura do girassol é necessário levar em consideração o potencial genético dos cultivares, as condições edafoclimáticas da região e as práticas de manejo empregadas na condução da cultura (LONG; FEIL; DIEPENBROCK, 2001; SILVEIRA et al., 2005).
Neste contexto, a avaliação da população de plantas e dos espaçamentos entre linhas para o cultivo de girassol são destacados em diversos trabalhos de pesquisa (SILVA; NEPOMUCENO, 1991; RIZZARD; SILVA, 1993; SILVA et al., 1995). A adoção de espaçamentos reduzidos na cultura proporciona vários benefícios, destacando a melhor distribuição de plantas na área e a maior interceptação de radiação solar pelas plantas (ANDRADE et al., 2002; ZAREA; GHALAVAND; DANESHIAN, 2005). Ressalta-se ainda que o uso de espaçamentos reduzidos proporciona o sombreamento mais rápido das entre linhas, diminuindo a perda de água por evaporação, diminuindo o impacto da gota de chuva na superfície do solo e melhorando a performance na aplicação de produtos fitossanitários. Além disto, reduz a mato competição, proporcionando efeito supressor no desenvolvimento das ervas daninhas (SILVA; NEPOMUCENO, 1991; SILVA et al., 1995).

Vantagens no uso de espaçamentos reduzidos visando aumento no rendimento de aquênios de girassol foram constatados por Andrade et al. (2002), além da maximização do uso de máquinas agrícolas pela adoção de um único espaçamento entre linhas para implantação de diferentes culturas como soja, milho, sorgo, feijão e girassol. A combinação ideal de híbridos de girassol com espaçamentos adequados pode permitir as plantas à exploração de maneira eficiente dos recursos ambientais (água, luz e nutrientes), proporcionando a obtenção de maiores rendimentos.

Sendo assim, o objetivo deste trabalho foi o de avaliar o efeito da redução do espaçamento na entre linha no desempenho agronômico de híbridos de girassol na região Centro-Oeste.

\section{Material e Métodos}

O ensaio foi instalado no campus experimental da FESURV-Universidade de Rio Verde, localizado no município de Rio Verde (GO), situado na latitude 
de $17^{\circ} 47^{\prime} 04^{\prime \prime}$ S e $50^{\circ} 57^{\prime} 33^{\prime \prime}$ W e altitude média de $716 \mathrm{~m}$. O solo é classificado como Latossolo Vermelho distrófico (EMPRESA BRASILEIRA DE PESQUISA AGROPECUÁRIA - EMBRAPA,
1999), cultivado no sistema de semeadura direta. Os dados referentes a precipitação e temperatura, por decêndio, no período de condução do experimento são apresentados na Figura 1.
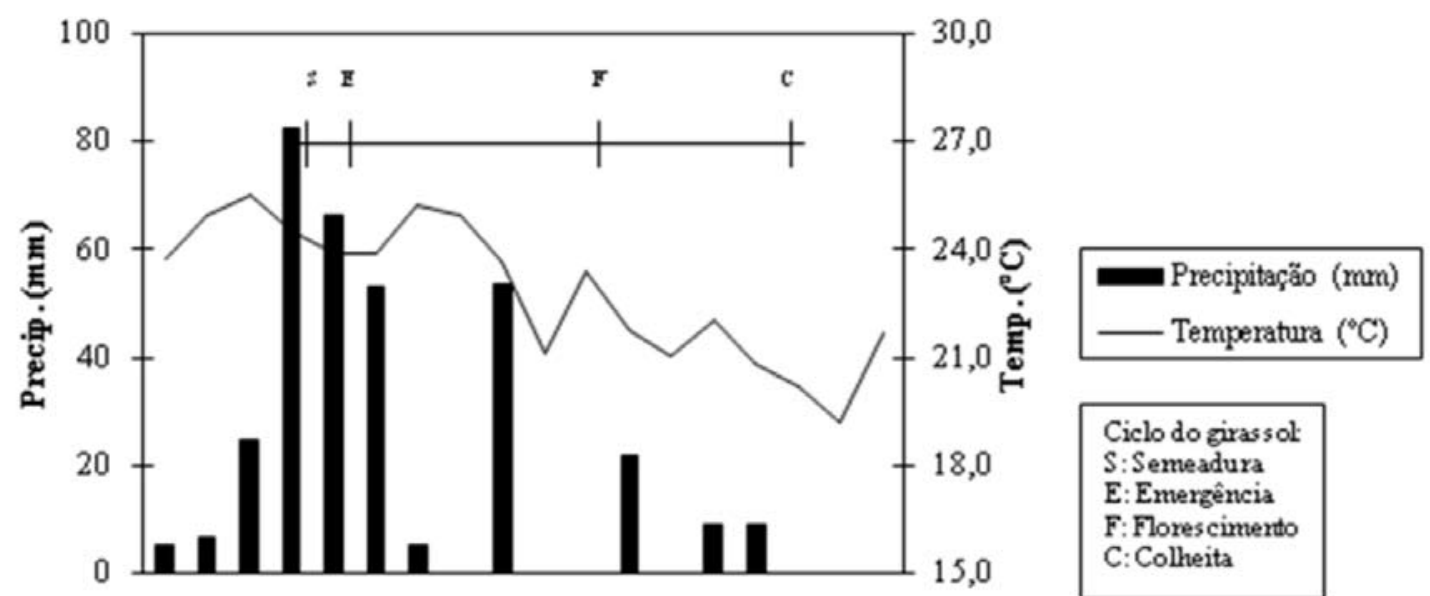

102028102031102030102031102030102031

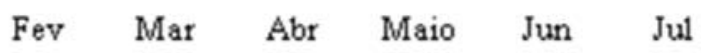

Ciclo do girassol

$S:$ Semeadura

E: Emergência

F: Florescimento

C: Colheita

Figura 1. Temperatura média do ar e precipitação pluvial, por decêndio, no período de fevereiro a julho de 2005 . Rio Verde (GO).

Foi empregado o delineamento experimental de blocos casualizados com os tratamentos em arranjo fatorial $2 \times 3$, com quatro repetições. Os tratamentos consistiram da combinação de dois espaçamentos na entre linha (40 e $50 \mathrm{~cm}$ ) com três híbridos de girassol (Agrobel 960, BRHS 5 e Hélio 251), totalizando 6 tratamentos. Cada parcela foi composta de 4 linhas de 5,0 $\mathrm{m}$ de comprimento. A área útil foi obtida eliminando as duas linhas laterais e $0,5 \mathrm{~m}$ de cada extremidade, apresentando portanto 3,2 e 4,0 $\mathrm{m}^{2}$ para os espaçamentos de 40 e $50 \mathrm{~cm}$, respectivamente.

Uma semana antes da instalação do ensaio foi realizada a dessecação da área experimental empregando o equivalente a 3,0 $\mathrm{L} \mathrm{ha}^{-1}$ de glifosato, com volume de calda de $150 \mathrm{~L} \mathrm{ha}^{-1}$. A semeadura dos híbridos de girassol foi realizada manualmente no dia 12 de março de 2005, sendo utilizado o equivalente de $300 \mathrm{~kg} \mathrm{ha}^{-1}$ do fertilizante 0820-18. Devido a limitação hídrica entre 20 a 30 dias após a emergência das plântulas (Figura 1), época recomendável para efetuar a cobertura com nitrogênio na cultura do girassol (SOUSA; LOBATO, 2004), não foi possível a realização desta prática.

Aos vinte dias após a emergência das plântulas, efetuou-se o desbaste visando obter a população final equivalente a 60.000 plantas ha $^{-1}$. Para evitar o efeito de plantas daninhas sobre o desenvolvimento dos híbridos de girassol, foram realizadas duas capinas manuais aos 20 e 40 dias após a emergência das plântulas. Não foi realizada aplicação de fungicida, bem como não foi feito uso de irrigação. Foi aplicado o equivalente a 2,0 1 ha $^{-1}$ do inseticida endossulfam em todas as parcelas visando o controle da lagarta preta do girassol (Chlosyne lacinia saundersii). A proteção dos capítulos com rede plástica, realizada aos quinze dias após o florescimento, foi necessária para evitar o ataque de pássaros. 
Acolheita foi realizada manualmente aos 115 dias após a semeadura, com $90 \%$ das plantas apresentando as brácteas dos capítulos com coloração amarelocastanho. As características avaliadas na área útil das parcelas foram: a) rendimento de aquênios: em $\mathrm{kg}$ ha $^{-1}$ corrigido para $13 \%$ de umidade; b) peso de 1.000 aquênios: em gramas escolhidos aleatoriamente dos capítulos; c) diâmetro do capítulo: em cm, através da medição aleatória em dez plantas de uma linha imaginária no centro do capítulo; d) número de aquênios por capítulo: obtido pela seguinte relação: (rendimento de aquênios x $1.10^{6}$ )/(peso de 1.000 aquênios x número de capítulos colhidos); e) altura de plantas: medição aleatória de dez plantas do colo até a inserção dos capítulos. Os dados coletados foram submetidos a análise de variância e as médias comparadas entre si pelo teste de Tukey a 5\% de probabilidade utilizando o programa SISVAR, versão 4.0 (FERREIRA, 2000).

\section{Resultados e Discussão}

Conforme resultados apresentados na Tabela 1 , não houve interação entre os híbridos de girassol e o espaçamento entre linhas. Entre as fontes de variação, apenas foram observadas significâncias para o efeito de híbrido no rendimento de aquênios e altura de plantas $(\mathrm{P} \leq 0,05$ e 0,01 , respectivamente) . Para o efeito de espaçamento entre linhas, a significância $(\mathrm{P} \leq 0,05)$ foi constatada para $\mathrm{o}$ rendimento de aquênios, peso de 1.000 aquênios e número de aquênios por capítulo.

Tabela 1. Resumo da análise de variância das características rendimento de aquênios (REND), peso de 1.000 aquênios (P1000A), diâmetro do capítulo (DC), número de aquênios por capítulo (NAC) e altura de plantas (AP). Rio Verde (GO).

\begin{tabular}{lcccccc}
\hline \multirow{2}{*}{ Fontes de Variação } & \multirow{2}{*}{ GL } & \multicolumn{5}{c}{ Quadrados Médios } \\
\cline { 3 - 7 } & 3 & REND & P1000A & DC & NAC & AP \\
\hline Blocos & 90.272 & 58,42 & 0,882 & 19.012 & 52,09 \\
Híbridos & 2 & $255.877^{*}$ & 13,03 & 1,032 & 73.131 & $644,05^{* *}$ \\
Espaçamentos & 1 & $268.144^{*}$ & $342,61^{*}$ & 1,215 & $164.805^{*}$ & 4,68 \\
Híbrido x Espaç. & 2 & 72.239 & 100,02 & 0,035 & 8.272 & 9,01 \\
Resíduo & 15 & 56.358 & 51,64 & 0,920 & 23.521 & 31,31 \\
\hline CV (\%) & & 20,36 & 12,04 & 8,17 & 40,36 & 6,05 \\
\hline
\end{tabular}

* e ** significativo a 5 e $1 \%$ de probabilidade, respectivamente.

Entre os híbridos de girassol, constatou-se rendimento de $1.372 \mathrm{~kg} \mathrm{ha}^{-1}$ para o Agrobel 960, sendo superior em $30 \%$ ao valor obtido com o híbrido Hélio 251, de menor rendimento (Tabela 2). Os valores observados com estes híbridos de girassol são inferiores aos obtidos em outros trabalhos (SILVA; NEPOMUCENO, 1991; RIZZARD; SILVA, 1993; SMIDERLE; MOURAO JÚNIOR; GIANLUPPI, 2005) e semelhantes aos de Solasi e Mundstock (1992). Uma das hipóteses para os baixos rendimentos obtidos foi a limitada disponibilidade hídrica para o crescimento dos capítulos e aquênios em estádios mais avançados de desenvolvimento das plantas de girassol (Figura 1), o que reflete as condições climáticas nos cultivos de safrinha na região Centro-Oeste. A limitação de água no solo proporciona diminuição no desenvolvimento das plantas de girassol, limitando o enchimento de aquênios a partir das reservas acumuladas nas folhas/ pecíolos, caule e capítulo (CASTRO; FARIAS, 2005). Como conseqüência se observa redução nos componentes do rendimento e consequentemente, decréscimos no rendimento final. 
Tabela 2. Valores médios de rendimento de aquênios (REND), peso de 1.000 aquênios (P1000A), diâmetro do capítulo (DC), número de aquênios por capítulo (NAC) e altura de plantas (AP) em função dos híbridos de girassol. Rio Verde (GO).

\begin{tabular}{lccccc}
\hline Híbridos de girassol & $\begin{array}{c}\text { REND } \\
\left(\mathrm{kg} \mathrm{ha}^{-1}\right)\end{array}$ & $\begin{array}{c}\text { P1000A } \\
(\mathrm{g})\end{array}$ & $\begin{array}{c}\text { DC } \\
(\mathrm{cm})\end{array}$ & NAC & $\begin{array}{c}\text { AP } \\
(\mathrm{cm})\end{array}$ \\
\hline Agrobel 960 & $1.372 \mathrm{a}^{*}$ & 58,6 & 11,6 & 489 & $82,2 \mathrm{~b}$ \\
BRHS5 & $1.069 \mathrm{ab}$ & 61,1 & 11,5 & 311 & $98,4 \mathrm{a}$ \\
Hélio 251 & $1.056 \mathrm{~b}$ & 59,4 & 12,2 & 340 & $97,1 \mathrm{a}$ \\
\hline Média & 1.167 & 59,7 & 11,8 & 380 & 92,6 \\
\hline
\end{tabular}

*Médias seguidas pela mesma letra na coluna não diferem entre si pelo teste de Tukey a $5 \%$ de probabilidade.

Para os componentes do rendimento (peso de 1.000 aquênios, diâmetro do capítulo e número de aquênios por capítulo) não foram observadas diferenças significativas entre os híbridos avaliados (Tabela 2). O valor médio de $59,7 \mathrm{~g}$, obtido para o peso de 1.000 aquênios, assemelha-se aos encontrados pelos autores (RIZZARD; SILVA, 1993; HECKLER, 2002). Apesar de não ter sido constatada significância para os componentes do rendimento entre os híbridos de girassol, vários autores destacam sua importância no aumento de rendimento na cultura (SOLASI; MUNDSTOCK, 1992; RIZZARD; SILVA, 1993; VIJAYAKUMAR et al., 2003; CASTRO; FARIAS, 2005). Para o diâmetro do capítulo, os resultados obtidos são considerados inferiores a outros trabalhos de pesquisa (SOLASI; MUNDSTOCK, 1992; SILVA; RIZZARD, 1993; HECKLER, 2002; TOMICH et al., 2003; SMIDERLE; MOURAO JÚNIOR; GIANLUPPI, 2005). Além disto, é comum ocorrer falha no enchimento, ou mesmo a ausência de aquênios no centro do capítulo do girassol. Isto é atribuído à maior demanda por fotoassimilados pelos aquênios oriundos das primeiras flores polinizadas (CASTRO; FARIAS, 2005). Associa-se a isto a baixa disponibilidade hídrica a partir do estádio de floração dos híbridos (Figura 1), aumentando o estresse hídrico na cultura. Isto limitou a formação e o enchimento de grãos no capítulo, influenciando de maneira semelhante os componentes do rendimento entre os híbridos avaliados.

Quanto ao porte das plantas de girassol, observase que os híbridos BRHS 5 e Hélio 251 apresentaram maior altura quando comparado ao Agrobel 960 (Tabela 2). Isto pode ser associado a precocidade do Agrobel 960, o que confere menor período de desenvolvimento das plantas. Por ter sido cultivado na safrinha com semeadura realizada em meados de março, ocasionando restrição na disponibilidade hídrica para as plantas de girassol, os resultados obtidos para a altura de plantas são considerados inferiores aos de outros autores (SILVA; RIZZARD, 1993; HECKLER, 2002; TOMICH et al., 2003).

$\mathrm{Na}$ análise do efeito do espaçamento entre linhas no rendimento de aquênios, pode-se observar que o espaçamento de $40 \mathrm{~cm}$ proporcionou maior rendimento (1.272 $\left.\mathrm{kg} \mathrm{ha}^{-1}\right)$, sendo superior em $20 \%$ o valor obtido no espaçamento de $50 \mathrm{~cm}(1.060$ $\mathrm{kg} \mathrm{ha}^{-1}$ ) (Tabela 3). O maior rendimento obtido no espaçamento de $40 \mathrm{~cm}$ pode ser atribuído, além de outros fatores, a adequada distribuição de plantas na área de cultivo, o que permite o melhor aproveitamento dos recursos naturais pelas plantas (ZAREA; GHALAVAND; DANESHIAN, 2005), principalmente quando estas apresentam menor estatura (92,6 cm, em média). 
Tabela 3. Valores médios de rendimento de aquênios (REND), peso de 1.000 aquênios (P1000A), diâmetro do capítulo (DC), número de aquênios por capítulo (NAC) e altura de plantas (AP) em função dos espaçamentos entre linhas de híbridos de girassol. Rio Verde (GO).

\begin{tabular}{cccccc}
\hline $\begin{array}{c}\text { Espaçamento entre } \\
\text { linhas } \\
(\mathrm{cm})\end{array}$ & REND & P1000A & DC & NAC & AP \\
& $\left(\mathrm{kg} \mathrm{ha}^{-1}\right)$ & $(\mathrm{g})$ & $(\mathrm{cm})$ & & $463 \mathrm{a}$ \\
\hline 40 & $1.272 \mathrm{a}^{*}$ & $55,9 \mathrm{~b}$ & 12,0 & 93,0 \\
50 & $1.060 \mathrm{~b}$ & $63,5 \mathrm{a}$ & 11,5 & $297 \mathrm{~b}$ & 92,1 \\
\hline Média & 1.166 & 59,7 & 11,8 & 380 & 92,6 \\
\hline
\end{tabular}

*Médias seguidas pela mesma letra na coluna não diferem entre si pelo teste de Tukey a 5\% de probabilidade.

O melhor arranjo de plantas na área de condução do ensaio pode também ter proporcionado maior disponibilização de fotoassimilados para a formação dos grãos nos capítulos, contribuindo para o aumento no rendimento de aquênios, como destacado por Solasi e Mundstock (1992). Além do incremento no rendimento, constatado por Andrade et al. (2002), o uso de espaçamentos reduzidos na cultura do girassol auxilia o controle de ervas daninhas na área de cultivo (SILVA; NEPOMUCENO, 1991; SILVA et al., 1995; SILVEIRA et al., 2005).

Na avaliação do peso de 1.000 aquênios, podese constatar o menor valor quando o girassol foi cultivado no espaçamento de $40 \mathrm{~cm}$, com apenas 55,9 g. No entanto quando se avalia o número de aquênios por capítulo, constata-se maior valor no espaçamento de $40 \mathrm{~cm}$, sendo $56 \%$ superior ao valor do espaçamento de $50 \mathrm{~cm}$. Nesta situação, o componente do rendimento número de aquênios por capítulo contribuiu para a obtenção de acréscimos no rendimento, compensando o decréscimo obtido com o peso de 1.000 aquênios (Tabela 3).

Quando se analisa os valores obtidos para o diâmetro do capítulo e altura de plantas, constatase que os resultados obtidos para os espaçamentos entre linhas não diferiram entre si, obtendo-se em média 11,8 e $92,6 \mathrm{~cm}$, respectivamente. Pelo fato do girassol ter sido cultivado na safrinha, onde há limitação hídrica em estádios mais avançados de desenvolvimento da cultura, os valores obtidos para o diâmetro do capítulo são considerados inferiores aos de Solasi e Mundstock (1992). Resultados obtidos por Nepomuceno e Silva (1992) constatam redução na altura de plantas de girassol e aumento do diâmetro do capítulo quando variou o espaçamento entre linhas de 1,0 para 0,4 m.

Os resultados obtidos demonstram o potencial de cultivo do girassol em espaçamentos reduzidos, o que permite otimizar as operações de semeadura de várias culturas na época da safrinha na região Centro-Oeste.

\section{Conclusões}

O híbrido de girassol Agrobel 96 apresenta maior rendimento de aquênios e menor porte de plantas, independente do espaçamento.

A redução do espaçamento entre linhas para $40 \mathrm{~cm}$ resultou em maior rendimento de aquênios e número de aquênios por capítulo, porém com redução no peso de 1.000 aquênios.

\section{Referências}

AMABILE, R. F.; FERNANDES, F.D.; SANZONOWICZ, C. Girassol como alternativa para o sistema de produção para o cerrado. Brasília: Embrapa Cerrados, 2002. (Circular Técnica, 20).

ANDRADE, F. H.; CALVINO, P.; CIRILO, A.; BARBIERI, P. Yield responses to narrow rows depend on increased radiation interception. Agronomy Journal, Madison, v. 94, n. 5, p. 975-980, 2002. 
CASTRO, C.; FARIAS, J. R. B. Ecofisiologia do girassol. In: LEITE, R. M. V. B. C.; BRIGHENTI, A. M.; CASTRO, C. (Ed.). Girassol no Brasil. Londrina: Embrapa Soja, 2005. p. 163-218.

EMPRESA BRASILEIRA DE PESQUISA AGROPECUÁRIA - EMBRAPA. Centro Nacional de Pesquisa de Solos. Sistema brasileiro de classificação de solos. Rio de Janeiro: Embrapa, 1999.

FERREIRA, D. F. Análises estatísticas por meio do Sisvar para Windows versão 4.0. In: REUNIÃO ANUAL DA REGIÃO BRASILEIRA DA SOCIEDADE INTERNACIONAL DE BIOMETRIA, 45., 2000, São Carlos, SP. Resumos... São Carlos: UFSCar, 2000. p. 255-258.

HECKLER, J. C. Sorgo e girassol no outono-inverno, em sistema plantio direto, no Mato Grosso do Sul, Brasil. Ciência Rural, Santa Maria, v. 32, n. 3, p. 517-520, 2002.

LONG, M.; FEIL, B.; DIEPENBROCK, W. Effects of plant density, row spacing and row orientation on yield and achene quality in rainfed sunflower. Acta Agronomica Hungarica, Budapest, v. 49, n. 4, p. 397-407, 2001.

NEPOMUCENO, A. L.; SILVA, P. R. F. Efeito do arranjo de plantas e da presença de ervas daninhas nas características de plantas associadas à colheita de girassol. Pesquisa Agropecuária Brasileira, Brasília, v. 27, n. 7, p. 1057-1063, 1992.

PEREIRA, F. A. R.; VELINI, E. D. Sistemas de cultivo no cerrado e dinâmica de populações de plantas daninhas. Planta Daninha, Viçosa, v. 21, n. 3, p. 355-363, 2003.

RIZZARD, M. A.; SILVA, P. R. F. Resposta de cultivares de girassol à densidade de plantas em duas épocas de semeadura. I - Rendimento de grãos e de óleo e componentes do rendimento. Pesquisa Agropecuária Brasileira, Brasília, v. 28, n. 6, p. 675-687, 1993.

ROSSI, R. O. Requerimentos ecológicos. In: (Ed.). Girassol. Curitiba: Tecnoagro, 1998. p. 175-182.

SILVA, P. R. F.; NEPOMUCENO, A. L. Efeito do arranjo de plantas no rendimento de grãos, componentes do rendimento, teor de óleo e no controle de plantas daninhas em girassol. Pesquisa Agropecuária Brasileira, Brasília, v. 26, n. 9, p. 1503-1508, 1991.

SILVA, P. R. F.; RIZZARD, M. A. Resposta de cultivares de girassol à densidade de plantas em duas épocas de semeadura. II - Características associadas à colheita. Pesquisa Agropecuária Brasileira, Brasília, v. 28, n. 6, p. 689-700, 1993.
SILVA, P. R. F.; RIZZARD, M. A.; TREZZI, M. M.; ALMEIDA, M. L. Densidade e arranjo de plantas em girassol. Pesquisa Agropecuária Brasileira, Brasília, v. 30, n. 6, p. 797-810, 1995.

SILVEIRA, J. M.; CASTRO, C.; MESQUITA, C. M.; PORTUGAL, F. A. F. Semeadura e manejo da cultura do girassol. In: LEITE; R. M. V. B. C.; BRIGHENTI, A. M.; CASTRO, C. (Ed.). Girassol no Brasil. Londrina: Embrapa Soja, 2005. p. 375-409.

SMIDERLE, O. J.; MOURAO JÚNIOR, M.; GIANLUPPI, D. Avaliação de cultivares de girassol em savana de Roraima. Acta Amazonica, Manaus, v. 35, n. 3, p. 331-336, 2005.

SODRÉ FILHO, J.; CARDOSO, A. N.; CARMONA, R.; CARVALHO, A. M. Fitomassa e cobertura do solo de culturas de sucessão ao milho na região dos cerrados. Pesquisa Agropecuária Brasileira, Brasília, v. 39, n. 4, p. 327-334, 2004.

SOLASI, A. D.; MUNDSTOCK, C. M. Épocas de semeadura e características do capítulo de cultivares de girassol. Pesquisa Agropecuária Brasileira, Brasília, v. 27, n. 6, p. 873-879, 1992.

SOUSA, D. M. G.; LOBATO, E. Calagem e adubação para culturas anuais e semiperenes. In: Cerrado: correção do solo e adubação. 2.ed. Brasília: Embrapa Informação Tecnológica, 2004. p. 283-316.

TOMICH, T. R.; RODRIGUES, J. A. S.; GONCALVES, L. C.; TOMICH, R. G. P.; CARVALHO, A. U. Potencial forrageiro de cultivares de girassol produzidos na safrinha para ensilagem. Arquivo Brasileiro de Medicina Veterinária e Zootecnia, Belo Horizonte, v. 55, n. 6, p. 756-762, 2003.

VIJAYAKUMAR, M.; SUBBIAN, P.; LOURDURAJ, A. C.; SELVARAJU, R. Effect of planting pattern and $\mathrm{N}$ splits on yield attributes, yield and quality of rainfed sunflower (Helianthus annuus L.). Acta Agronomica Hungarica, Budapest, v. 51, n. 2, p. 157-162, 2003.

ZAREA, M. J.; GHALAVAND, A.; DANESHIAN, J. Effect of planting patterns of sunflower on yield and extinction coefficient. Agronomy for Sustainable Development, Paris, v. 25, n. 4, p. 513-518, 2005. 
